\title{
Predictors of therapeutic treatment outcome in adolescent chronic tic disorders
}

\author{
J. B. Nissen, E. T. Parner and P. H. Thomsen
}

\section{Background}

Chronic tic disorders may have a major impact on a child's function. A significant effect has been shown for combined habit reversal training (HRT) and exposure response prevention (ERP) treatment delivered in an individual and group setting.

\section{Aims \\ The present study examines predictors and moderators of treatment outcome after an acute therapeutic intervention.}

\section{Method}

Fifty-nine children and adolescents were randomised to manualised treatment combining HRT and ERP as individual or group training. Age, gender, baseline tic severity, Premonitory Urge for Tics Scale (PUTS) scores, Beliefs about Tic Scale (BATS) scores, hypersensitivity and comorbid psychiatric symptoms were analysed as predictors of outcome. The same characteristics were examined as moderators for individual versus group treatment. Outcome measures included the change in total tic severity (TTS) score and functional impairment score (as measured by the Yale Global Tic Severity Scale (YGTSS)).

\section{Results}

Internalising symptoms predicted a lesser decrease in functional impairment. The occurrence of obsessive-compulsive symptoms predicted a larger decrease in TTS. Baseline hypersensitivity and high scores on depressive symptoms favoured individual treatment. High baseline PUTS scores favoured group therapy.

\section{Conclusions}

This is the first study examining factors predicting and moderating perceived functional impairment following a therapeutic intervention. The study adds to the knowledge on predictors and moderators of TTS. Furthermore, this is the first study examining the effect of the BATS score. The study points towards factors that may influence treatment outcome and that require consideration when choosing supplemental treatment. This applies to comorbid anxiety and depressive symptoms, and to the child's belief about their tics and premonitory urge.

\section{Declaration of interest}

None.

\section{Keywords}

Tourette syndrome; paediatric; predictor; habit reversal training; exposure response prevention.

\section{Copyright and usage}

(c) The Royal College of Psychiatrists 2019. This is an Open Access article, distributed under the terms of the Creative Commons Attribution-NonCommercial-NoDerivatives licence (http://creativecommons.org/licenses/by-nc-nd/4.0/), which permits noncommercial re-use, distribution, and reproduction in any medium, provided the original work is unaltered and is properly cited. The written permission of Cambridge University Press must be obtained for commercial re-use or in order to create a derivative work.

\section{Chronic tic disorder in children and adolescents}

Chronic tic disorders including Tourette syndrome are neurodevelopmental disorders affecting $0.5-1 \%$ of children and adolescents. The disorders are characterised by the occurrence of motor and/ or vocal tics. The course of the tic disorder may be very fluctuating both in intensity, symptom presentation and localisation. ${ }^{1-4}$ Behavioural and psychosocial interventions are recommended as the primary treatment in children and adolescents ${ }^{5}$ where therapeutic treatments include habit reversal training (HRT) and exposure response prevention (ERP). ${ }^{5}$

\section{Habit reversal training and exposure response prevention in tic treatment}

The treatment effect of $\mathrm{HRT}^{6}$ has been examined in several randomised controlled trials showing a significant reduction of tic intensity both as a total score with effect sizes of $0.68,{ }^{7} 0.57^{8}$ and $1.50,{ }^{9}$ and as a reduction in tic severity, as measured by the Yale Global Tic Severity Scale (YGTSS) ${ }^{10}$ of 37.5\%, ${ }^{11}$ Furthermore, a significant reduction has been shown for separate scores for motor and vocal symptoms, and impairment (effect sizes of 0.49 (motor), 0.50 (vocal) and 0.57 (impairment)). ${ }^{7,8}$ A single randomised controlled trial examined the effect of ERP ${ }^{12}$ compared with HRT. ${ }^{13}$ Effect sizes of 1.42 and 1.06 were found for ERP and HR, respectively. No difference could be found between HRT and ERP. ${ }^{13}$

In an open randomised controlled clinical trial, Nissen et al ${ }^{14}$ examined the effectiveness of a treatment manual combining
HRT and ERP delivered in an individual and a group setting. The study showed a significant reduction in total tic severity (TTS) score with an effect size of 1.26 and in functional impairment score (as measured by the YGTSS) with an effect size of 1.41. Apart from the functional impairment score, there was no difference between the individual setting and group therapy. ${ }^{14}$

\section{Predictors and moderators in tic treatment}

To optimise treatment outcome, an understanding of predictors and moderators of treatment outcome could prove important.

In a study from 2017, Sukhodolsky et al ${ }^{15}$ examined predictors on treatment response following Comprehensive Behavioural Intervention for Tics (CBIT) or supportive therapy. They demonstrated that a higher tic severity at baseline and positive expectations of treatment predicted a greater tic improvement following CBIT, whereas anxiety disorders and premonitory urge severity predicted a lower tic reduction. ${ }^{15}$ Other studies have not been able to establish a relation between premonitory urges and tic inhibition. ${ }^{16}$ In a sample of both children and adults, McGuire et al showed that different clusters of tic symptoms did not predict treatment response, and they concluded that therapeutic treatment with CBIT/HRT was effective over a range of tic types. ${ }^{17}$

Sukhodolsky et al also examined moderators of treatment response. ${ }^{15}$ They showed that tic medication moderated treatment response, where tic reduction following CBIT was unaffected by tic medication, whereas medication was associated with a greater tic reduction after supportive therapy. Other psychiatric disorders 
such as attention-deficit hyperactivity disorder, obsessive-compulsive disorder or anxiety disorders, age, gender, family functioning, symptom characteristics or treatment expectancy did not moderate treatment response. ${ }^{15}$ In a study by Houghton et al, ${ }^{18}$ habituation was examined as the process leading to tic reduction mediated through a decrease in premonitory urge severity. Reductions in premonitory urge could not be proved to moderate treatment outcome, thus questioning the role of habituation in therapeutic treatment procedures. In conclusion, the knowledge on predictors for therapeutic treatment outcome is scarce in children and adolescents. The most convincing factors, however, seem to be tic severity at baseline, the magnitude of premonitory urge, expectations for treatment and the occurrence of anxiety disorders.

Tic severity in childhood is an important predictor for future quality of life as rated in adults. ${ }^{19}$ Therefore, the availability of an effective treatment for childhood tic disorders is important.

Previously, we have described a significant positive outcome of treatment in individual as well as in group settings. ${ }^{14}$ The aim of the present study was to examine possible predictors of treatment outcome in an open randomised controlled clinical trial examining the effectiveness of a combined treatment of HRT and ERP in children and adolescents with chronic tic disorders. The study focused on predictors and mediators for treatment outcome after an acute therapeutic intervention in all participants. Furthermore, the study examined moderators for treatment outcome in groups compared with individual treatment.

\section{Method}

The open randomised controlled clinical trial is described elsewhere. ${ }^{14}$ In brief, children and adolescents referred to the specialised Tourette out-patient clinic at the Department of Child and Adolescent Psychiatry, Aarhus University Hospital, Psychiatry, Denmark, and diagnosed with a chronic tic disorder were randomised to manualised treatment including HRT and ERP delivered either as individual training or training in groups of four. The treatment for both the individual and group setting was based on a newly designed manual ${ }^{20}$ describing an eight-session treatment plus a booster session. During the sessions, the participants were trained in both HRT and ERP. In the individual therapy, the parents participated in the last 15 min of each session, whereas in the group setting the parents participated at the end of the second, fourth, eighth and ninth session. ${ }^{14}$ The therapy was conducted by a trained and supervised psychologist, a child and adolescent psychiatrist, and a teacher.

The study was approved by the National Ethical Committee (1-10-72-216-15) and the Danish Data Protection Agency (1-1602-490-15), registered 12 October 2015. Oral and written information was given to parents and patients, and written consent from patients over 15 years and parents were received.

Diagnostic eligibility was established using a modified version of the Schedule for Affective Disorders and Schizophrenia for SchoolAge Children - Present and Lifetime version (K-SADS-PL) ${ }^{21}$ administered to the parent and child/adolescent separately. The K-SADS-PL information was used to confirm a primary diagnosis of chronic tic disorder and to ensure that none of the exclusion criteria were met. Exclusion criteria included symptoms or disorders that required immediate treatment. Thus, patients with psychotic disorders, severe depression, suicidal ideation or attempts and severe anorexia nervosa were excluded. Furthermore, children and adolescents with an IQ below 70, a lifetime diagnosis of pervasive developmental disorder, or treatment with HRT or ERP during the past 6 months were excluded. If sufficient treatment was offered for the comorbid primary condition, or if medication for tics or other psychiatric disorders was stable, the patients were included in the treatment study. ${ }^{14}$ At baseline and at the eighth session, the participants completed Screen for Child Anxiety Related Emotional Disorders (SCARED), ${ }^{22}$ the Mood and Feelings Questionnaire $(\mathrm{MFQ})^{23}$ the Premonitory Urge Scale (PUTS $)^{24}$ and Beliefs About Tics Scale (BATS). ${ }^{25}$ The parents completed SCARED, the MFQ, Child Behaviour Checklist (CBCL), ${ }^{26}$ and the Sensory Profile, ${ }^{27}$ where the parents were asked about their child's sensitivity during childhood and adolescence. ${ }^{14}$

The main outcome measures were TTS (motor score + vocal score) and functional impairment as evaluated by YGTSS, and a positive responder status, defined as a more than $25 \%$ reduction in severity scores. ${ }^{28}$ Evaluations of treatment response were made by an independent evaluator who was not masked to the treatment allocation, yet not involved in the treatment of the patient and masked to any previous evaluations. The evaluators were a specialised psychologist and a child and adolescent psychiatrist with several years of experience in diagnosing, evaluating and treating tic disorders. A random sample of 18 patients was audiotaped (10\%) and evaluated by another rater with extensive experience and expertise in the use of the YGTSS. The analysis revealed that the intraclass correlation coefficient was 0.88 (95\% CI 0.72-0.95) for TTS (motor and vocal tics) and 0.89 (95\% CI 0.74-0.95) for functional impairment. ${ }^{14}$

\section{Predictor and moderator variables}

Predictors are characteristics affecting response regardless of treatment assignment. Based on a recent study, ${ }^{15}$ we selected the following baseline variables as potential predictors of treatment outcome: age, gender, tic severity at baseline (YGTSS TTS and functional impairment scores), the magnitude of premonitory urge (PUTS), expectations of treatment (Likert scale: how much do you believe in the treatment $0-4$ ) and the occurrence of comorbid symptoms or disorders (modified KSADS, CBCL, SCARED, MFQ). Since hypersensitivity may be associated with premonitory urge, Sensory Profile scores were included in the analyses. In a study by Leclerc et $a l^{29}$ it was shown that a cognitive and psychophysiological programme with focus on processes influencing thoughts and behaviours underlying tics had a positive effect on tic severity and improved self-esteem post-treatment. Therefore, the present study also examined the effect of basic beliefs evaluated using the BATS. The same baseline variables were examined as moderators that could influence differential response to individual therapy compared with group therapy. Changes in the PUTS score $\left(\right.$ PUTS $\left._{\text {diff }}\right)$ and BATS score $\left(\right.$ BATS $\left._{\text {diff }}\right)$ (baseline - post-treatment) were correlated to treatment outcome.

\section{Statistics}

The associations between baseline characteristics and outcome measures after eight treatment sessions were expressed as mean differences using linear regression analysis. Similarly, the associations between baseline characteristics and responder rate were expressed as risk difference using binary regression.

The correlation between the change in BATS or PUTS and outcome measures were further analysed in a multiple linear regression analysis. We similarly performed correlation analysis for the responder rate using binary regression.

The moderation of difference in treatment outcome between individual and group setting by baseline characteristics were examined in a multiple linear regression analysis by including an interaction between the treatment type and the baseline characteristics. 
We similarly performed a moderator analysis for the responder rate using binary regression.

A $P<0.05$ was considered statistically significant. Given the exploratory nature of the moderator and predictor analysis, the study did not correct for multiple comparisons.

\section{Results}

\section{Characteristics of the participants}

A total of 102 children and adolescents were screened and 59 (mean age 12.24 years, $9-17$ years; males $n=37(62.7 \%))$ were randomly assigned to either individual treatment $(n=31$, mean age 12.30 years), or treatment in a group setting ( $n=28$, mean age 12.18 years). A total of 54 children and adolescents participated throughout the study (individual setting $n=27$; group setting $n=27$ ).

\section{Predictors for treatment outcome for the whole group}

Baseline anxiety scores (SCARED scores) evaluated by the parents predicted a significantly lesser decrease in functional impairment scores (functional impairment diff $_{\text {) }}$ (SCARED parent mean difference -0.21 ( $95 \% \mathrm{CI}-0.37$ to -0.04$), P=0.017$ ) (Table 1$)$. Age predicted a larger decrease in functional impairment (mean difference 2.30 (95\% CI 1.3-3.3), $P=0.001$ ).

The occurrence of obsessive-compulsive symptoms predicted a larger reduction in the change in TTS (mean difference 4.24 (95\% CI $0.33-8.14), P=0.034)$. Furthermore, baseline TTS predicted a larger TTS at eighth session (mean difference 0.41 (95\% CI 0.18-0.64), $P=0.001$ ). However, a greater baseline severity also predicted a greater reduction from baseline to eighth session (mean difference 0.59 (95\% CI 0.36-0.82), $P=0.001$ ). When the TTS at baseline was dichotomised into moderate severity (YGTSS TTS $\leq 29$ ) or marked severity (YGTSS TTS $>29$ ), marked severity predicted a significantly lower end score at eighth session (mean difference -0.95 (95\% CI -1.88 to -0.03 ), $P=0.04$ ). This was different for lower severity scores (mean difference 0.56 (95\% CI 0.24-0.88), $P=$ 0.001). Baseline functional impairment did not predict the end score at eighth session (mean difference 0.19 (95\% CI -0.05 to
$0.43), P=0.12$ ). However, a greater baseline severity predicted a greater functional difference reduction from baseline to eighth session (mean difference 0.81 (95\% CI 0.57-1.05), $P=0.001$ ) There was a trend that an increased sensitivity to noises and sounds was associated with an increased functional impairment at eighth session mean difference 3.19 ( $95 \%$ CI -0.58 to 6.96), $P=0.10)$ (data not shown)

\section{Predictor of achieving responder status}

A positive responder status was defined as a reduction of more than $25 \%$ in severity score. ${ }^{28}$ Responder status was independent of CBCL scores, age, gender, comorbidity and baseline severity (Table 1).

\section{Correlation between change in BATS and PUTS scores and change in TTS and functional impairment}

As shown in Table 2, there was a significant correlation between changes in BATS scores from baseline to the eighth session $\left(\right.$ BATS $\left._{\text {diff }}\right)$ and the reduction in functional impairment score (functional impairment diff $_{\text {) }}$ (mean difference 0.43 (95\% CI 0.17 $0.69), P=0.002$ ). Comparably, after correcting for baseline functional impairment score, there was an inverse correlation between the BATS $_{\text {diff }}$ and functional impairment at eighth session (mean difference -0.27 ( $95 \% \mathrm{CI}-0.46$ to -0.09$), P=0.005)$. There was no correlation between BATS $_{\text {diff }}$ and change in TTS $\left(\mathrm{TTS}_{\text {diff }}\right)$ or responder rates. There was no correlation between the changes of PUTS score from baseline to post-treatment (PUTS $\left.{ }_{\text {diff }}\right)$ and functional impairment $_{\text {diff }}$ or TTS $_{\text {diff. However, after correcting for baseline }}$ functional impairment score, there was an inverse correlation

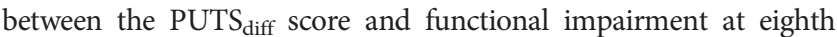
session (mean difference -0.32 (mean difference -0.63 to -0.02 ), $P=0.038)$.

\section{Moderators for individual versus group treatment outcome}

See Table 3 (and supplementary Fig. 1a-f, available at https://doi. org/10.1192/bjo.2019.56). In relation to functional impairment scores, the presence of hypersensitivity and high scores on the

Table 1 The associations as mean difference or risk difference between each baseline variable and treatment outcome measured as change in total tic severity (TTS) score $\left(\mathrm{TTS}_{\text {diff }}\right.$ ), change in functional impairment score (functional impairment ${ }_{\text {diff }}$ ) and responder rate

\begin{tabular}{|c|c|c|c|}
\hline & $\begin{array}{l}\text { TTS }_{\text {diff, }} \text { mean } \\
\text { difference }(95 \% \mathrm{CI}) P\end{array}$ & $\begin{array}{l}\text { Functional impairment } \\
\text { mean diff, } \\
\text { difference }(95 \% \mathrm{Cl}) P\end{array}$ & $\begin{array}{l}\text { Responder rate, TTS risk } \\
\text { difference }(95 \% \mathrm{CI}) P\end{array}$ \\
\hline Gender, male $(n=35)$ & $2.20(-1.65$ to 6.06$) 0.26$ & -0.78 (-6.27 to 4.71$) 0.78$ & $0.05(-0.21$ to 0.32$) 0.69$ \\
\hline Age & $0.54(-0.29$ to 1.37$) 0.20$ & 2.30 (1.30 to 3.30$) 0.001 *$ & $0.017(-0.03$ to 0.07$) 0.53$ \\
\hline Just-right & $2.83(-1.22$ to 6.88$) 0.17$ & $2.30(-3.40$ to 8.01$) 0.42$ & $0.14(-0.14$ to 0.42$) 0.33$ \\
\hline Sensitivity & $1.82(-2.95$ to 6.59$) 0.45$ & $1.09(-5.65$ to 7.84$) 0.75$ & $0.08(-0.25$ to 0.42$) 0.63$ \\
\hline Obsessive-compulsive symptoms & 4.24 (0.33 to 8.14) $0.034^{*}$ & $0.82(-4.92$ to 6.56$) 0.78$ & $0.24(-0.05$ to 0.52$) 0.10$ \\
\hline Coping strategies & $-1.83(-5.59$ to 1.93$) 0.33$ & $0.64(-4.63$ to 5.90$) 0.81$ & $-0.14(-0.39$ to 0.11$) 0.28$ \\
\hline Child Behaviour Checklist & $-0.04(-0.11$ to 0.03$) 0.26$ & -0.09 ( -0.18 to 0.02$) 0.10$ & $-0.002(-0.007$ to 0.003$) 0.45$ \\
\hline SCARED, child & $-0.02(-0.16$ to 0.12$) 0.73$ & $-0.04(-0.24$ to 0.16$) 0.67$ & $-0.007(-0.02$ to 0.002$) 0.15$ \\
\hline SCARED, parents & $-0.06(-0.18$ to 0.06$) 0.33$ & $-0.21(-0.37$ to -0.04$) 0.017^{*}$ & $-0.003(-0.01$ to 0.005$) 0.46$ \\
\hline Mood and Feelings Questionnaire child & $0.13(-0.41$ to 0.67$) 0.64$ & $0.22(-0.57$ to 1.00$) 0.58$ & $0.001(-0.04$ to 0.04$) 0.95$ \\
\hline Mood and Feelings Questionnaire parents & $-0.009(-0.36$ to 0.34$) 0.96$ & $-0.33(-0.82$ to 0.18$) 0.20$ & $0.004(-0.02$ to 0.03$) 0.76$ \\
\hline Anxiety & $2.26(-2.29$ to 6.81$) 0.31$ & 0.99 (-8.96 to 10.9) 0.84 & $-0.12(-0.49$ to 0.26$) 0.53$ \\
\hline Attention-deficit hyperactivity disorder & $-1.59(-7.06$ to 3.88$) 0.55$ & $-3.61(-15.3$ to 8.06$) 0.53$ & $-0.08(-0.48$ to 0.32$) 0.71$ \\
\hline Planning to structure & $4.14(-1.04$ to 9.33$) 0.11$ & $-9.17(-20.2$ to 1.87$) 0.10$ & - \\
\hline Obsessive-compulsive disorder & $-0.55(-6.55$ to 5.45$) 0.85$ & $7.96(-4.35$ to 20.3$) 0.19$ & $0.01(-0.46$ to 0.48$) 0.96$ \\
\hline TTS, baseline & 0.59 (0.36 to 0.82 ) $0.001^{*}$ & - & $0.007(-0.012$ to 0.03$) 0.46$ \\
\hline Functional impairment, baseline & - & 0.81 (0.57 to 1.05$) 0.001^{*}$ & - \\
\hline Beliefs About Tic Scale, baseline & $0.01(-0.19$ to 0.21$) 0.90$ & $0.13(-0.17$ to 0.42$) 0.39$ & $-0.008(-0.02$ to 0.004$) 0.20$ \\
\hline Premonitory Urge for Tics Scale, baseline & $-0.03(-0.37$ to 0.30$) 0.84$ & $0.25(-0.24$ to 0.74$) 0.30$ & $-0.008(-0.03$ to 0.01$) 0.50$ \\
\hline
\end{tabular}


Table 2 The associations as mean difference or risk difference between Belief About Tic Scale (BATS), respectively Premonitory Urge for Tics scale (PUTS) and outcome measures.

\begin{tabular}{|c|c|c|c|}
\hline & $\begin{array}{l}\text { TS }_{\text {diff, }} \text { mean } \\
\text { difference }(95 \% \mathrm{Cl}), P\end{array}$ & $\begin{array}{l}\text { Functional impairment } \\
\text { mean diff, } \\
\text { difference }(95 \% \mathrm{Cl}), P\end{array}$ & $\begin{array}{l}\text { Responder TTS risk } \\
\text { difference }(95 \% \mathrm{Cl}), P\end{array}$ \\
\hline $\begin{array}{l}\text { BATS }_{\text {diff }} \text { (baseline - eighth session) } \\
\text { (PUTS }_{\text {diff }} \text { (baseline - eighth session) }\end{array}$ & $\begin{array}{r}0.08(-0.12 \text { to } 0.28) 0.42 \\
-0.18(-0.49 \text { to } 0.13) 0.24\end{array}$ & $\begin{array}{l}0.43(0.17 \text { to } 0.69) 0.002^{*} \\
0.13(-0.32 \text { to } 0.59) 0.56\end{array}$ & $\begin{array}{r}0.004(-0.01 \text { to } 0.02) 0.54 \\
-0.0005(-0.02 \text { to } 0.02) 1.00\end{array}$ \\
\hline
\end{tabular}

MFQ (both parents' and children's evaluation) and on the CBCL favoured individual treatment. If the child was not diagnosed with anxiety, individual therapy showed the most favourable outcome. High baseline PUTS scores moderated TTS at the eighth session and responder rate favouring group therapy. In contrast, but comparable with functional impairment high scores of MFQ (parent) favoured individual treatment.

\section{Discussion}

\section{Main findings}

The present study examined predictors and moderators of treatment outcome in children and adolescents diagnosed with a chronic tic disorder and treated with a combination of HRT and ERP. The study showed that internalising disorders (anxiety) predicted a lesser reduction in functional impairment, whereas TTS score at baseline predicted severity at post-treatment. Furthermore, beliefs about the tic symptoms were shown to have a negative influence on treatment outcome, and several baseline characteristics such as anxiety, a high score on premonitory urge, baseline sensitivity and a high score on the MFQ could moderate treatment outcome depending on the therapeutic setting. To our knowledge, this is the first study examining factors predicting and moderating perceived functional impairment following a therapeutic intervention. The study adds to the knowledge on predictors and moderators for treatment outcome evaluated by TTS score. Furthermore, this is the first study examining the predicting and moderating effect of a child's belief about their tic symptoms as measured by the BATS questionnaire.

\section{Interpretation of our findings}

The predictor analysis identified a few variables that affected posttreatment outcome regardless of treatment assignment. High scores on parental ratings of the child's anxiety predicted a lesser decrease in functional impairment scores (functional impairment diff). $_{\text {f }}$. Occurrence of comorbid symptoms such as anxiety may influence treatment outcome and not least the way the child perceives the impairment related to the tic disorder. Sukhodolsky et al ${ }^{15}$ also showed that co-occurring anxiety disorders were associated with less tic reduction after treatment. They proposed incorporation of more active anxiety and stress management strategies. ${ }^{15}$ The results from the present study support these considerations and emphasise the importance of identifying the occurrence of anxiety and depressive symptoms.

Increased age predicted an increased reduction in the perceived impairment. Thus, adolescents may experience an even better effect on their general well-being and function. Several of the participants

\begin{tabular}{|c|c|c|c|}
\hline Moderator & $\begin{array}{l}\text { TS at eight session, difference in } \\
\text { mean difference }(95 \% \mathrm{Cl}) P^{\mathrm{b}}\end{array}$ & $\begin{array}{l}\text { Responder TTS, difference in risk } \\
\text { difference }(95 \% \mathrm{CI}) P^{\mathrm{b}}\end{array}$ & $\begin{array}{l}\text { Functional impairment score at eight session, } \\
\text { difference in mean difference }(95 \% \mathrm{Cl}) P^{\mathrm{b}}\end{array}$ \\
\hline Age & $0.64(-0.95$ to 2.23$) 0.42$ & $0.03(-0.09$ to 0.16$) 0.63$ & $-0.67(-2.49$ to 1.15$) 0.46$ \\
\hline $\begin{array}{l}\text { Beliefs About Tic Scale } \\
\text { score, baseline }\end{array}$ & $0.02(-0.33$ to 0.37$) 0.91$ & $0.007(-0.02$ to 0.04$) 0.60$ & $-0.08(-0.49$ to 0.31$) 0.66$ \\
\hline $\begin{array}{l}\text { Premonitory Urge for } \\
\text { Tics Scale score, } \\
\text { baseline }\end{array}$ & 0.66 (0.10 to 1.22$) 0.02^{*}$ & -0.05 (-0.09 to 0.0006$) 0.053^{*}$ & $-0.07(-0.76$ to 0.62$) 0.83$ \\
\hline $\begin{array}{l}\text { Child Behaviour } \\
\text { Checklist score }\end{array}$ & $-0.10(-0.22$ to 0.02$) 0.11$ & 0.0007 (-0.010 to 0.01$) 0.90$ & $-0.13(-0.26$ to 0.004$) 0.057$ \\
\hline Anxiety & $-0.44(-10.5$ to 9.6) 0.93 & $0.22(-0.62$ to 1.06$) 0.60$ & $11.88(-0.11$ to 23.86$) 0.052^{*}$ \\
\hline $\begin{array}{l}\text { Attention-deficit } \\
\text { hyperactivity } \\
\text { disorder }\end{array}$ & $5.43(-8.43$ to 19.3$) 0.42$ & $0.47(-0.72$ to 1.66$) 0.42$ & $6.92(-11.45$ to 25.28$) 0.44$ \\
\hline $\begin{array}{l}\text { Obsessive-compulsive } \\
\text { disorder }\end{array}$ & $5.87(-8.42$ to 20.2$) 0.40$ & $-0.57(-1.78$ to 0.64$) 0.33$ & 10.55 (-7.92 to 29.01) 0.25 \\
\hline Planning and structure & $-3.77(-15.5$ to 7.92$) 0.51$ & $-0.22(-1.18$ to 0.74$) 0.63$ & $-9.44(-24.43$ to 5.5$) 0.20$ \\
\hline Sensitivity & $-6.75(-15.4$ to 1.94$) 0.13$ & $0.20(-0.50$ to 0.89$) 0.58$ & -10.06 (-19.65 to -0.48$) 0.04$ * \\
\hline SCARED, parents & $-0.21(-0.45$ to 0.03$) 0.08$ & 0.004 (-0.02 to 0.03$) 0.77$ & $-0.09(-0.34$ to 0.16$) 0.49$ \\
\hline SCARED, child & $-0.09(-0.35$ to 0.17$) 0.49$ & $0.0034(-0.02$ to 0.03$) 0.75$ & $-0.24(-0.51$ to 0.04$) 0.086$ \\
\hline $\begin{array}{l}\text { Mood and Feelings } \\
\text { Questionnaire, } \\
\text { parents }\end{array}$ & $-0.71(-1.31$ to -0.10$) 0.023^{*}$ & $-0.002(-0.05$ to 0.05$) 0.94$ & $-0.73(-1.37$ to -0.09$) 0.026^{*}$ \\
\hline $\begin{array}{l}\text { Mood and Feelings } \\
\text { Questionnaire, child }\end{array}$ & $-0.63(-1.56$ to 0.30$) 0.18$ & $0.0067(-0.07$ to 0.09$) 0.87$ & $-1.49(-2.47$ to -0.51$) 0.004^{*}$ \\
\hline
\end{tabular}


rated increased feeling of control as even more important than the reduction in tic symptoms. ${ }^{14}$ This increased feeling of control may be very important in the socially active lives of the adolescents.

Participants with greater baseline severity of motor and vocal tics experienced a higher end score of motor and vocal tic severity. However, dichotomising baseline TTS scores into moderate severity (YGTSS TTS $\leq 29$ ) or marked severity (YGTSS TTS >29), marked severity predicted a significant lower end score at eighth session. Thus, the overall higher end score of motor and vocal tic severity may cover a differential effect of baseline severity scores, supporting that patients with severe tic disorders may benefit from therapeutic interventions. This finding is in accordance with the European recommendation of behavioural and psychosocial intervention as the primary treatment in children and adolescents independent of severity of the tic disorder. ${ }^{5}$ The occurrence of obsessive-compulsive symptoms predicted a larger reduction in TTS. Obsessive-compulsive symptoms are closely related to tic symptoms and it may often be difficult to distinguish these symptoms, especially from the complex tics. Likewise, the recommended treatment of obsessive-compulsive symptoms is comparable with tic treatment. Thus, children and adolescents with obsessive-compulsive symptoms may have experienced an effect on both these symptoms and the tics and may have rated both as a reduction in tic symptoms. However, the results emphasise that obsessive-compulsive symptoms are no hindrance to a positive outcome of tic treatment. The severity of premonitory urge did not predict treatment outcome in the present study. This finding is in contrast to the findings of Sukhodolsky et al. ${ }^{15}$ However, the PUTS scores showed no significant difference from baseline to the eighth session, ${ }^{14}$ which is in accordance with a study from 2013 that showed that urge ratings did not decline during the following prolonged tic suppression. ${ }^{30}$

There was a significant positive correlation between the reduction in BATS scores and a decrease in perceived functional impairment. Even though the result does not point to causality, the finding suggests that persistent thoughts may have a negative influence on treatment outcome as measured by the child's experience of general function. Classical behavioural treatment of tics does not include cognitive elements. However, a child's experience of how much the tic symptoms impact on everyday life is dependent on the child's interpretation of the tic symptoms. The BATS questionnaire includes questions on how tics and premonitory urge may affect the child if the child suppresses tics. Thus, a high score on the BATS indicates intense thoughts concerning the necessity to tic as soon as the child feels a bodily sensation. In a study by Leclerc et $a l^{29}$ it was shown that a cognitive and psychophysiological programme with focus on processes influencing thoughts and behaviours underlying tics had a positive effect on tic severity and improved self-esteem post-treatment. It could therefore prove important to include a baseline examination of possible thoughts, and to include cognitive elements in the treatment procedures. However, beliefs or thoughts about tic, and perceived functional impairment seem to be dynamic parameters. Since the scores were evaluated at the same time point, a reduction in perceived functional impairment may also have had a positive influence on the child's general thoughts about their tics, including an achieved experience of enhanced control.

The reduction of premonitory urge did not correlate with the change in perceived functional impairment, whereas the reduction was inversely correlated to functional impairment at eighth session. Even though the severity of premonitory urge at baseline did not predict treatment outcome, the course of the premonitory urge during treatment may influence how impaired the child continues to feel despite a reduction in motor and vocal tic severity. As many children and adolescents may not experience habituation to the premonitory urge, it is important that treatment includes teaching about how the child learns to accept and endure the urge feeling.

\section{Individual versus group treatment}

Several baseline characteristics moderated treatment outcome differentially to the treatment setting. A high PUTS score, anxiety and a low CBCL score at baseline favoured treatment in groups as evaluated by TTS and functional impairment. In contrast, increased sensitivity at baseline and a high score on the MFQ favoured individual treatment. Thus, the predictor analysis showed that anxiety symptoms predicted a lower treatment outcome, and the moderator analysis further showed that these factors differentially influence the response to individual versus group treatment. Thus, comorbidity may influence treatment outcome in tic treatment, and it may therefore be necessary to incorporate more active treatment modalities focusing on mood and anxiety disorders. A high score on sensitivity favoured individual treatment. Increased sensitivity to external stimulus may be associated with increased sensitivity or increased attention to inner stimulus as well. In an individualised setting, the therapist might have a better opportunity to train endurance of sensitivity along with training of competing response and exposure. A high PUTS score favoured a group setting. Training together with peers may help to endure the premonitory urge and distract the attention from these unpleasant sensations.

\section{Limitations}

The results should be considered in the light of limitations. The number of participants is rather low, which is especially important for the moderator analysis. This renders interpretation of the results more difficult. Furthermore, given the exploratory nature of the moderators and predictor analysis, the study did not correct for multiple comparisons. Another important limitation is the lack of masking of the evaluators although the evaluators did not take an active part in the treatment course and they were masked for previous evaluations. Finally, there is no control condition, which may render it difficult to distinguish between predictors specific to active treatment versus to a more general improvement.

Overall, the combined treatment of HRT and ERP in an individual setting or in groups is helpful to reduce tic intensity and perceived impairment in children and adolescents with a chronic tic disorder. ${ }^{14}$ However, the present study points towards factors that may influence treatment outcome and that therefore require consideration when choosing supplemental treatment strategies. This applies for the occurrence of comorbid anxiety or depressive symptoms, but also for the child's own belief about their tics and the premonitory urge sensation. Other co-occurring psychiatric conditions or the feeling of not-just-right did not moderate treatment effects. Thus, in spite of these other conditions, the combined treatment delivered both individually and in groups is effective in reducing the overall tic severity and impairment in children and adolescents.

\section{Implications for clinical practice}

(a) Occurrence of internalising disorders (anxiety) predicted a lesser reduction in functional impairment.

(b) TTS score at baseline predicted severity at post-treatment.

(c) Beliefs or thoughts about tics may have a negative influence on treatment outcome.

(d) The course of premonitory urge may be related to perceived impairment post-treatment.

(e) Baseline anxiety and a high score on premonitory urge moderate treatment outcome and favour a group setting. Children reporting high baseline sensitivity and a high score on the MFQ may have a better outcome in an individual setting. 
J. B. Nissen (D. PhD, Senior Doctor and Research Associate Professor, Department of Child and Adolescent Psychiatry, Aarhus University Hospital; and Institute of Clinical Medicine, Health, Aarhus University, Denmark; E. T. Parner, Professor, Section of Biostatistics, Department of Public Health, Aarhus University, Denmark; P. H. Thomsen, Professor, Department of Child and Adolescent Psychiatry, Aarhus University Hospital: and Institute of Clinical Medicine, Health, Aarhus University, Denmark

Correspondence: Judith Nissen, Department of Child and Adolescent Psychiatry, Aarhus University Hospital, Psychiatry, Palle Juul-Jensens Blvd. 99, DK-8200 Aarhus, Denmark. Email: judiniss@rm.dk

First received 27 Jun 2018, final revision 22 May 2019, accepted 25 Jun 2019

\section{Funding}

Principal investigator Judith Nissen was partly supported by the Lundbeck Foundation, Grant number R185-2014-2486. The study was performed during clinical practice.

\section{Acknowledgements}

The statistical expert for the study was Professor Erik Thorlund Parner. I also want to acknowledge Helle Veller Mortensen for excellent linguistic assistance.

\section{Supplementary material}

Supplementary material is available online at https://doi.org/10.1192/bjo.2019.56.

\section{References}

1 Jankovic J. Tourette syndrome. Phenomenology and classification of tics. Neurol Clin 1997; 15: 267-75.

2 Cohen SC, Leckmanc JF, Bloch MH. Clinical assessment of Tourette syndrome and tic disorders. Neurosci Biobehav Rev 2013; 37: 997-1007.

3 Cath DC, Hedderly T, Ludolph AG, Stern JS, Murphy T, Hartmann A, et al. European clinical guidelines for Tourette syndrome and other tic disorders. Part I: assessment. Eur Child Adoelsc Psychiatry 2011; 20: 155-71.

4 Evans J, Seri S, Cavanna AE. The effects of Gilles de la Tourette syndrome and other chronic tic disorders on quality of life across the lifespan: a systematic review. Eur Child Adolesc Psychiatry 2016; 25: 939-48.

5 Martino D, Pringsheim TM. Tourette syndrome and other chronic tic disorders: an update on clinical management. Expert Rev Neurother 2018; 18: 125-37.

6 Woods DW, Piacentini JC, Chang SW, Deckersbach T, Ginsberg GS, Peterson AL, et al. Managing Tourette Syndrome: A Behavioral Intervention for Children and Adults. University Press, 2003.

7 Piacentini J, Woods DW, Scahill L, Wilhelm S, Peterson AL, Chang S, et al. Behavior therapy for children with Tourette disorder: a randomized controlled trial. JAMA 2010; 303: 1929-37.

8 Wilhelm S, Peterson AL, Piacentini J, Woods DW, Deckersbach T, Sukhodolsky DG, et al. Randomized trial of behavior therapy for adults with Tourette syndrome. Arch Gen Psychiatry 2012; 69: 795-803.

9 Wilhelm S, Deckersbach T, Coffey BJ, Bohne A, Peterson AL, Baer L. Habit reversal versus supportive psychotherapy for Tourette's disorder: a randomized controlled trial. Am J Psychiatry 2003; 160: 1175-7.

10 Leckman JF, Riddle MA, Hardin MT, Ort SI, Swartz KL, Stevenson J, et al. The Yale Global tic severity scale: initial testing of a clinician-rated scale of tic severity. J Am Acad Child Adolesc Psychiatry 28: 566-73.

11 Deckersbach T, Rauch S, Buhlmann U, Wilhelm S. Habit reversal versus supportive psychotherapy in Tourette's disorder: a randomized controlled trial and predictors of treatment response. Behav Res Ther 2006; 44: 1079-90.

12 Verdellen CWJ, van de Griendt J, Kriens S, van Oostrum I, Chang I. Tics-Therapist Manual and Workbook for Children. Boom Cure and Care, 2011.
13 Verdellen CW, Keijsers GP, Cath DC, Hoogduin CA. Exposure with response prevention versus habit reversal in Tourette's syndrome: a controlled study. Behav Res Ther 2004; 42: 501-11.

14 Nissen JB, Kaergaard M, Laursen L, Parner E, Thomsen PH. Combined habit reversal training and exposure response prevention in a group setting compared to individual training: a randomized controlled clinical trial. Eur Child Adolesc Psych 2019; 28: 57-68.

15 Sukhodolsky DG, Woods DW, Piacentini J, Wilhelm S, Peterson AL, Katsovich L, et al. Moderators and predictors of response to behaviour therapy for tics in Tourette syndrome. Neurology 2017; 88: 1029-36.

16 Ganos C, Kahl U, Schunke O, Kühn S, Haggard P, Gerloff C, et al. Are premonitory urges a prerequisite of tic inhibition in Gilles de la Tourette syndrome? J Neurol Neurosurg Psychiatry 2012; 83: 975-8.

17 McGuire JF, Nyirabahizi E, Kircanski K, Piacentini J, Peterson AL, Woods DW, et al. A cluster analysis of tic symptoms in children and adults with Tourette syndrome: clinical correlates and treatment outcome. Psych Res 2013; 210: 1198-204.

18 Houghton DC, Capriotti MR, Scahill LD, Wilhelm S, Peterson AL, Walkup JT, et al. Investigating habituation to premonitory urges in behavior therapy for tic disorders. Behav Ther 2017; 48: 834-46.

19 Cavanna AE, David K, Orth M, Robertson MM. Predictors during childhood of future health-related quality of life in adults with Gilles de la Tourette syndrome. Eur J Paediatr Neurol 2012; 16: 605-12.

20 Nissen JB, Kaergaard M, Laursen L. Niks til Tics. Therapist Manual and Working Book for the Children and Adolescents. Akademisk Forlag, 2018

21 Kaufman J, Birmaher B, Brent D, Rao U, Flynn C, Moreci P, et al. Schedule for Affective Disorders and Schizophrenia for School-Age Children. Present and Lifetime Version (K-SADS-PL): initial reliability and validity data. J Am Acad Child Adolesc Psychiatry 1997; 36: 980-88.

22 Birmaher B, Khetarpal S, Brent D, Cully M, Balach L, Kaufman J, et al. The Screen for Child Anxiety Related Emotional Disorders (SCARED): scale construction and psychometric characteristics. J Am Acad Child Adolesc Psychiatry 1997; 36: $545-53$.

23 Wood A, Kroll L, Moore A, Harrington R. Properties of the mood and feelings questionnaire in adolescent psychiatric outpatients: a research note. J Child Psychol Psychiatry 1995; 136: 327-34

24 Woods DW, Piacentini J, Himle MB, Chang S. Premonitory Urge for Tics Scale (PUTS): initial psychometric results and examination of the premonitory urge phenomenon in youths with Tic disorders. J Dev Behav Pediatr 2005; 26: 397-403.

25 Steinberg T, Harush A, Barnea M, Dar R, Piacentini J, Woods D, et al. Tic-related cognition, sensory phenomena, and anxiety in children and adolescents with Tourette syndrome. Compr Psychiatry 2013; 54: 462-66.

26 Achenbach TM. Child behavior checklist and related instruments. In The Use of Psychological Testing for Treatment Planning and Outcome Assessment (ed ME Maurish). Lawrence Erlbaum Associates, 1994.

27 Dunn W. Sensory Profile 2 Manual. The Psychological Corporation, Pearson, 2014.

28 Jeon S, Walkup JT, Woods DW, Peterson A, Picentinin J, Wilhelm S, et al. Detecting a clinically meaningful change in tic severity in Tourette syndrome: a comparison of three methods. Contemp Clin Trials 2013; 36: 414-20.

29 Leclarc JB, O'Connor KP, Nolin GJ, Valois P. Lavoie ME The effect of a new therapy for children with tics targeting underlying cognitive, behavioral, and physiological processes. Front Psych 2016; 7: 135.

30 specht MW, Woods DW, Nicotra CM, Kelly LM, Ricketts EJ, Conelea CA, et al. Effects of tic suppression: ability to suppress, rebound, negative reinforcement, and habituation to the premonitory urge. Behav Res Ther 2013; 51: $24-30$. 